\title{
Anti-Endothelial Autoantibodies in Patients With Sudden Hearing Loss
}

\author{
Fabrizio Ottaviani, MD; Gabriella Cadoni, MD; Luca Marinelli, MD; Anna Rita Fetoni, MD; \\ Antonella De Santis, MD; Anna Romito, MD; Paola Vulpiani, MD; Raffaele Manna, MD
}

\begin{abstract}
Objectives/Hypothesis: Sudden hearing loss (HL) can be caused by autoimmune disorders localized to the inner ear or secondary to systemic immune diseases. Studies in autoimmune animal strains showing HL have reported changes in the cochlear stria vascularis. The authors investigated the presence of antiendothelial cell antibodies (AECA) to see if immunemediated vasculitis may play a role in human sudden HL. Study Design: A prospective study in patients with sudden HL. Methods: Fifteen consecutive patients (mean age, 32 y) affected by sudden $H L$ and 14 normal subjects were included. Patients with familial deafness and metabolic diseases were excluded. Extensive audiovestibular, imaging, microbiological, immunological, and routine examinations were performed. AECA were detected on rat kidney tissue sections on the sera collected at $-20^{\circ} \mathrm{C}$. Results: AECA were positive in 8 of 15 patients (53\%) ( 2 of 5 men and 6 of 10 women), thus differing significantly from the normal control population, in which only 2 of 14 tested AECA positive $(P=.023)$. Conclusions: In patients with sudden $H$, immune-mediated vascular damage can have a pathogenetic role and AECA might represent a serological marker of vasculitis. Key Words: Sudden hearing loss, immune-mediated vascular damage, anti-endothelial cell antibodies.
\end{abstract}

Laryngoscope, 109:1084-1087, 1999

\section{INTRODUCTION}

Sudden hearing loss (HL) is defined as a sensorineural $\mathrm{HL}$ of $30 \mathrm{~dB}$ or more over at least three contiguous audiometric frequencies that develops over a period of a few hours to 3 days ${ }^{1}$ and whose etiology can be found only in $10 \%$ to $15 \%$ of patients. ${ }^{2} \mathrm{McCabe}{ }^{3}$ reported in 1979 that a group of patients with HL responded well to immunosuppressive treatment with steroids and cyclophosphamide and described autoimmune inner ear disease as a clinical entity. Recently there has been considerable in-

From the Departments of Otorhinolaryngology (F.O., G.C., L.M., A.R.F.) and Internal Medicine (A.D.S., A.R., P.V., R.M.) of the Catholic University of the Sacred Heart, Rome, Italy. 31,1999

Editor's Note: This Manuscript was accepted for publication March

Send Reprint Requests to Fabrizio Ottaviani, MD, Institute of Otorhinolaryngology of the Catholic University of the Sacred Heart, Largo Agostino Gemelli, 8. I-00168 Rome, Italy. E-mail: iclot@rm.unicatt.it vestigation into the relationship between immune system and sensorineural HL. Harris ${ }^{4}$ demonstrated the inner ear's capacity to respond to local antigenic challenge and to produce systemic immunization. Local and systemic immunization was documented experimentally after administration of nonspecific $c^{4-6}$ or inner-ear-specific antigens. 7,8

Several authors have described a significant increase of specific HLA class II genes, ${ }^{9}$ elevated levels of circulating immune complexes ${ }^{10,11}$ and the detection of inner ear autoantibodies in patients with progressive or sudden sensorineural HL. ${ }^{12-14}$ These data are consistent with an immune-mediated hypothesis of sudden HL. Nevertheless, the existence of autoimmune sudden HL has not been demonstrated yet and the response to immunosuppressive treatment cannot be used as a diagnostic criterion.

Evidence also indicates that sensorineural HL can be a manifestation of systemic autoimmune disease ${ }^{15}$ such as Cogan's syndrome, ${ }^{16}$ temporal arteritis, ${ }^{17}$ Wegener's granulomatosis, ${ }^{18}$ polyarteritis nodosa, ${ }^{19}$ and systemic lupus erythematosus. ${ }^{20}$ Although the vascular damage frequently observed in lupus erythematosus and other vasculitides is probably mediated by immune complexes, ${ }^{21}$ autoantibodies against endothelial cells (AECA) have also been implicated in this process and could have a pathogenetic role. ${ }^{22}$ Indeed AECA may damage endothelial cells via a complement-mediated or antibody-dependent cellular cytotoxic mechanism, or by upregulation of adhesion molecules and increased secretion of proinflammatory and chemoattractant cytokines. ${ }^{22}$ The aim of this paper is to verify if a vascular damage could have a pathogenetic role and if AECA might represent a serological marker of vasculitis in patients affected by idiopathic sudden HL.

\section{PATIENTS AND METHODS}

Fifteen consecutive patients (mean age, $32 \mathrm{y}$; age range, $14-50$ y; 10 females, 5 males) affected by sudden HL were included. Patients with familial deafness and metabolic diseases were excluded. Table I shows the various types of HL. All patients underwent a routine general physical examination. Extensive audiovestibular (pure-tone average, speech discrimination, impedance audiometry, auditory brainstem response, electronystagmogram, computed dynamic posturography), imaging (magnetic resonance imaging, epi-aortic-vessels doppler ultrasound), micro- 
TABLE I.

Clinical Characteristics and Laboratory Data of 15 Patients With Sudden Hearing Loss.

\begin{tabular}{|c|c|c|c|c|c|c|c|c|c|c|c|}
\hline $\begin{array}{l}\text { Patient } \\
\text { No. }\end{array}$ & Flat L.oss & High-Tone Loss & U-Shaped Loss & Low-Tone Loss & ESR & CRP & $\mathrm{ClC}$ & ACA & ANA & Anti-DNA ds & AECA \\
\hline 1 & $\begin{array}{c}\text { Severe } \\
\text { (bilateral) }\end{array}$ & - & - & - & High & High & Normal & - & - & - & + \\
\hline 2 & Severe & - & - & - & Normal & Normal & Normal & - & - & - & + \\
\hline 3 & Severe & - & - & - & Normal & Normal & Normal & - & + & - & - \\
\hline 4 & 一 & Severe & - & - & Normal & Normal & Normal & - & NA & - & + \\
\hline 5 & 一 & Severe & - & - & Normal & Normal & Elevated & - & + & - & + \\
\hline 6 & - & Moderate & - & - & Normal & Normal & Elevated & - & + & - & + \\
\hline 7 & Moderate & - & - & - & Normal & Normal & Normal & - & - & - & - \\
\hline 8 & - & - & - & Moderate & Normal & Normal & Normal & - & - & - & + \\
\hline 9 & - & - & - & Moderate & Normal & Normal & Normal & - & - & - & - \\
\hline 10 & - & - & - & Moderate & Normal & High & Elevated & - & + & - & - \\
\hline 11 & - & - & Moderate & - & Normal & Normal & Elevated & - & + & - & - \\
\hline 12 & - & - & Moderate & - & Normal & Normal & Normal & - & - & - & - \\
\hline 13 & Mild & - & - & - & Normal & Normal & Elevated & - & - & - & + \\
\hline 14 & - & - & - & Mild & Normal & Normal & Elevated & - & + & + & - \\
\hline 15 & Severe & - & - & - & Normal & Normal & Normal & - & - & - & + \\
\hline
\end{tabular}

$\mathrm{CPR}=\mathrm{C}$ reactive protein; $\mathrm{ESR}=$ erythrosedimentation rate; $\mathrm{CIC}=$ circulating immunocomplexes; $\mathrm{ANA}=$ antinuclear antibodies; $\mathrm{AECA}=$ antiendothelial cell antibodies; $\mathrm{ACA}=$ anticardiolipin antibodies; $\mathrm{NA}=$ not available.

biological (herpesvirus, cytomegalovirus, influenza and parainfluenza virus, Epstein-Barr virus, coxsackie virus, hepatitis B and $C$ virus, Venereal Disease Research Laboratory), immunological (antinuclear, anti-DNA double stranded, anticardiolipin, antiendothelial cell antibodies, immunocomplexes), and routine examination (blood hemoglobin and leukocyte count, erythrocyte sedimentation rate, serum gamma-globulin, $\mathrm{C}$ reactive protein) work-ups were performed.

Median follow-up was 4 months (range, $2-7 \mathrm{mo}$ ). A 1-year follow-up for AECA detection has been established. Fourteen normal subjects ( 7 men and 7 women; mean age, $29 \mathrm{y}$; age range, $17-45$ y) without history of HL or autoimmune or metabolic diseases were included as controls.

Sera were drawn from 15 patients and from 14 control subjects and collected at $-20^{\circ} \mathrm{C}$. All samples of blood were obtained 1 day after the date of hospitalization and 3 days or less after the onset of sudden HL.

The AECA detection was performed as described by Tan and Pearson ${ }^{2: 3}$ and is based on the principle of indirect fluorescent antibody technique. The specific antibodies were detected on rat kidney tissue sections, which were coated onto the slides as monolayer (Biogenetics, Padua, Italy). In the first step, the human serum, diluted at 1:20 with PBS buffer solution, was brought into contact with the antigen substrate. Negative and positive human controls were provided with the kit (Biogenetics). The antibody, present in the test serum, attached to the antigen to form an antigen-antibody complex. Unbound material was removed by washing. In the next step, the antigen-antibody complexes were marked by specific antihuman polyvalent globulin conjugated to fluorescein (FITC). The positive reaction was shown by a green fluorescence peritubular vessel in kidney sections and observed in inverted fluorescence microscope. $\chi^{2}$ test (StatView 4.0-Macintosh) was performed to compare the patient and control groups.

\section{RESULTS}

Sudden HL was unilateral in 14 cases; only one case came to our observation with a bilateral HL, which was

Laryngoscope 109: July 1999 flat and severe. In unilateral cases, HL was severe in five cases, moderate in seven, and mild in two. No characteristic shape was detected, but U-shaped and low-tone losses were more frequently associated with less severe HL (Table I). Audiological tests showed the presence of recruitment and the absence of pathological adaptation in all cases. A retrocochlear lesion was excluded by means of impedance tests and auditory brainstem response when possible (auditory threshold) and by imaging techniques. Normal vestibular reflectivity was present in all patients.

Anticardiolipin autoantibodies were negative in all patients. Antinuclear autoantibodies were positive in 6 of 14 patients (one missing) (42.8\%). AECA were positive in 8 of 15 patients ( $53 \%$ ) ( 2 of 5 males and 6 of 10 females), thus significantly differing from the normal population, in which only 2 of 14 tested AECA positive $(P=.023)$. Although the number of patients was small, we did observe that severe hearing losses tended to be associated with positive AECA ( 5 of 6 ), whereas mild and moderate hearing losses were more frequently associated with negative $\operatorname{AECA}(6$ of 9 ).

Titers examined for IgM antivirus were negative in all patients. The relationship among AECA and other parameters (immunological or otherwise) is showed in Table I. After corticosteroid immunosuppressive therapy (methylprednisone $1 \mathrm{mg} / \mathrm{kg}$ per day for $1 \mathrm{mo}$ ) no AECApositive patients had a significant recovery, but they did show a reduction of inflammatory parameters (erythrocyte sedimentation rate, $C$ reactive protein) without worsening of hearing or new symptoms.

\section{DISCUSSION}

The evidence in humans of coexisting sensorineural HL and systemic autoimmune disease has suggested the

Ottaviani et al.: Autoantibodies in Sudden Hearing Loss 
possibility of isolated forms of immune-mediated deafness. The results of treatment of individual cases with immunosuppressive agents also support the hypothesis that some cases of so-called "idiopathic" sudden HL are immune-mediated. ${ }^{12,24}$ Response to immunosuppressive treatment can be demonstrated by a reduction of inflammatory parameters and by the absence of other systemic or local manifestations and not only by a recovery of hearing. Moreover, long-term studies are necessary to determine if autoimmune sudden $\mathrm{HL}$ is an initial local manifestation of a systemic autoimmune disease or if it is an isolated entity.

This is the first report of AECA in sudden HL. The pathogenetic potential of AECA has been demonstrated in vascular diseases, especially for immune-mediated vasculitis. ${ }^{25}$ For this reason, and because AECA were present in $53 \%$ of our patients (8/15), we suspect that AECA induced vascular damage of the inner ear in these cases.

In fact, AECA, reacting against available surface antigens, may damage endothelial cells via a complementmediated or antibody-dependent cellular cytotoxic mechanism, or by upregulation of adhesion molecules. Although AECA do not display any disease specificity, their absence in diseases such as mixed essential cryoglobulinemia, in which vascular damage is clearly mediated by other immune effectors, suggests that these antibodies represent a primary event rather than merely a secondary immune response against antigens exposed in the course of the vascular inflammatory process. ${ }^{22}$

The hypothesis that vascular damage might have a pathogenetic role in immune-mediated sudden HL is supported by labyrinthine fibrosis and cochlear ossification found in patients affected by autoimmune diseases and sudden HL, ${ }^{26}$ and by the observation of the breakdown of stria vascularis blood-labyrinth barrier in $\mathrm{C} 3 \mathrm{H} / \mathrm{ppr}$ autoimmune disease mice that have elevated auditory brainstem response thresholds during the active phase of the disease. Some researchers suggest that either a humoral mechanism of injury or a direct injury to the endothelial cells is involved and that the breakdown of tight junctions between stria vascularis endothelial cells may be one etiologic mechanism of sensorineural HL in autoimmune disease. ${ }^{27}$

In our AECA-positive patients, the absence of HL recovery after steroid therapy might be explained by irreversible vascular damage of the inner ear, as described in patients with sudden HL and systemic vasculitis. ${ }^{26}$ Therefore, the immunosuppressive treatment cannot be utilized as the only diagnostic criterion.

The finding in our patients of antinuclear antibodies (42.8\%) and circulating immunocomplexes (40\%) also supports the involvement of immune mechanisms in this disease and is consistent with the experimental model of autoimmune inner ear disease of $\mathrm{C} 3 \mathrm{H} / \mathrm{hpr}$ mouse where significantly elevated threshold shifts correlated with development of antinuclear antibodies and circulating immunocomplexes. ${ }^{28}$

A systemic disease should produce bilateral rather than unilateral ear symptoms over time. In fact, unilateral symptoms more often result from primary ear disease (e.g., eighth nerve schwannoma and chronic otitis media), but, as in ocular autoimmune diseases, ${ }^{29,30}$ the microvascular damage may be unilateral. Moreover, the finding of AECA supports a vascular hypothesis and should encourage investigation about the existence of an immune systemic disease.

The preponderance of women in our group of patients with sudden HL is noted in other autoimmune diseases. This link to the female sex may be influenced by endocrine effects on the immune system, but the cause remains unclear.

\section{CONCLUSION}

The present data suggest an immunological mechanism in the pathogenesis of some cases of idiopathic sudden HL. Detection of serological nonspecific inner-ear autoantibodies, such as AECA, in patients with sudden HL. may be useful in clinical practice to identify a subset of sudden HL patients whose inner ear damage may be caused by immune-mediated vasculitis. The diagnosis of AECA-related autoimmune sudden HL should support an aggressive immunosuppressive treatment to avoid the worsening of $\mathrm{HL}$ or the onset of new symptoms. Further studies on a larger population are needed to support this hypothesis and to demonstrate the possible role of autoantibodies such as AECA in the development of immunemediated sudden HL.

\section{BIBLIOGRAPHY}

1. Wilson WR, Byl FM, Laird N. The efficacy of steroids in the treatment of idiopathic sudden hearing loss. Arch Otolar. yngol 1980;106:772-776.

2. Mattox DE, Lyles CA. Idiopathic sudden sensorineural hearing loss. Am J Otol 1989;10:242-247.

3. MeCabe BF. Autoimmune sensorineural hearing loss. Ann Otol Rhinol Laryngol 1979;88:585-589.

4. Harris JP. Immunology of the inner ear: response of the inner ear to antigen challenge. Otolaryngol Head Neck Surg 1983;91:18-23.

5. Yoo TJ, Yazawa Y, Floyd R, Tomoda K. Antibody activity in perilymph from rats with type II collagen-induced autoimmune ear disease. Ann Otol Rhinol Laryngol 1984;13:1-2.

6. Tomoda K, Maeda N, Yamawaki T. Immunologically induced experimental hydrops. In: JB Nadol, ed. Meniere's Disease. Amsterdam: Kugler \& Ghedini; 1989:165-172.

7. Harris JP. Experimental autoimmune hearing loss, Laryngoscope 1987;97:63-76.

8. Soliman AM. Experimental autoimmune ear disease. Laryngoscope 1989;99:188-193.

9. Cao MV,Thonnard J, Deggouj $N$, et al. HLA class IIassociated genetic susceptibility in idiopathic progressive sensorineural hearing loss. Ann Otol Rhinol Laryngol 1996;105:628-633.

10. Brookes GB. Immune complex-associated deafness: preliminary communication. $J R$ Soc Med 1985;78:47-54.

11. Gutierrez F, Moreno PM, Sainz M. Relationship between immune complex and total hemolytic complement in en dolymphatic hydrops. Laryngoscope 1994;104:1495-1498.

12. Harris JP, Sharp PA. Inner ear autoantibodies in patients with rapidly progressive sensorineural hearing loss. $\mathrm{La}$ ryngoscope 1990;100:516-24.

13. Hughes GB, Moscicki R, Barna BP, San Martin JE. Laboratory diagnosis of immune inner ear disease. Am $J$ Otol 1994;15:198-202.

14. Hughes GB, Kinney SE, Barna BP, Calabrese LH. Practical versus theoretical management of autoimmune inner ear disease. Laryngoscope 1984;94:758-767.

15. Veldman JE. The immune system in hearing disorders. Acta Otolaryngol (Stock) 1988;(suppl 458):67-75.

Ottaviani et al.: Autoantibodies in Sudden Hearing Loss 
16. Cote IN, Molony TB, Waxman J, Parsa D. Cogan's syndrome manifesting as sudden bilateral deafness: diagnosis and management. South Med $J$ 1993;86:1056-1060.

17. Wolfovitz E, Levy Y, Brook JG. Sudden deafness in a patient with temporal artheritis. $J$ Rheum 1987;14:384-385.

18. Kempf HG. Ear involvement in Wegener's granulomatosis. Clin Otolaryngol 1989;14:451-456.

19. Rowe-Jones JM, Macallan DC, Srooshian M. Polyarteritis nodosa presenting as bilateral sudden onset cochleovestibular failure in a young woman. $J$ Laryngol Otol 1990; 104:562-564.

20. Bowman CA, Linthicum FH, Nelson RA, Mikami K, Quismorio $\mathrm{F}$. Sensoryneural hearing loss associated with systemic lupus erythematosus. Otolaryngol Head Neck Surg 1986; 94:197-204.

21. Westphal JR, Boerbooms AM, Schalkwijk CJ, et al. Antiendothelial cell antibodies in sera patients with autoimmune diseases: comparison between ELISA and FACS analysis. Clin Exp Immunol 1994;96:444-449.

22. Meroni PL, D'Cruz D, Khamashta M, Youinou O, Hughes GRV. Anti-endothelial cell antibodies: only for scientists or for clinicians too? Clin Exp Immunol 1996;104:199-202.

23. Tan EM, Pearson CM. Rheumatic disease sera reactive with capillaries in the mouse kidney. Arthritis Rheum 1972;15: $23-28$.
24. MacCabe BF. Autoimmune inner-ear disease: results of therapy. In CR Pfaltz, W Arnold, O Kleinsasser, eds Bearing of basic research on clinical otolaryngology. Adv Otorhinolar yngol. Basel: Karger; 1991:46:78-81.

25. Hill MB, Phipps JL, Milford-Ward A, Greaves M, Hughes P. Further characterization of anti-endothelial cell antibodies in systemic lupus erythematosus by controlled immunoblotting. Br J Rheumatol 1996;35:1231-1238.

26. Yoon TH, Paparella MM, Schachern PA. Systemic Vasculitis: a temporal bone histopathologic study. Laryngoscope 1989; 99:600-609.

27. Lin DW, Trune DR. Breakdown of stria vascularis bloodlabyrinth barrier in $\mathrm{C} 3 \mathrm{H} / \mathrm{lpr}$ autoimmune disease mice Otolaryngol Head Neck Surg 1997;117:530-534.

28. DR Trune. Cochlear immunoglobulin in the $\mathrm{C} 3 \mathrm{H} / \mathrm{lpr}$ mouse model for autoimmune hearing loss. Otolaryngol Head Neck Surg 1997;117:504-508.

29. Lyons JL, Rosenbaum JT. Uveitis associated with inflammatory bowel disease compared with uveitis associated with spondyloarthropathy. Arch Ophthalmol 1997;115:61-64.

30. Bykovskaia GN, Slepova OS, Krichevskaia GI, Katargina LA Kushnir VN. Study of antibodies to DNA in patients with bilateral and unilateral endogenous uveitis. Vestn Oftalmol 1997;113:30-32. 